The University of San Francisco

USF Scholarship: a digital repository @ Gleeson Library |

Geschke Center

2017

\title{
Perspectives on the Indigenous Worldviews in Informal Science Education Conference
}

Aparna Venkatesan

University of San Francisco, avenkatesan@usfca.edu

A. Burgasser

Follow this and additional works at: https://repository.usfca.edu/phys

Part of the Bilingual, Multilingual, and Multicultural Education Commons, and the Science and Mathematics Education Commons

\section{Recommended Citation}

Venkatesan, A. \& Burgasser, A. (2017). Perspectives on the Indigenous Worldviews in Informal Science Education Conference. The Physics Teacher, 55, 456-459. https://doi.org/10.1119/1.5008336

This Article is brought to you for free and open access by the College of Arts and Sciences at USF Scholarship: a digital repository @ Gleeson Library | Geschke Center. It has been accepted for inclusion in Physics and Astronomy by an authorized administrator of USF Scholarship: a digital repository @ 


\section{Perspectives on the Indigenous Worldviews in Informal Science Education Conference}

Aparna Venkatesan, and Adam Burgasser

Citation: The Physics Teacher 55, 456 (2017);

View online: https://doi.org/10.1119/1.5008336

View Table of Contents: http://aapt.scitation.org/toc/pte/55/8

Published by the American Association of Physics Teachers

\section{Articles you may be interested in}

The Hunt for Red October II: A magnetohydrodynamic boat demonstration for introductory physics

The Physics Teacher 55, 460 (2017); 10.1119/1.5008337

Elastic and Inelastic Collisions of a Ball with a Wood Block

The Physics Teacher 55, 467 (2017); 10.1119/1.5008338

Simple Pencil-and-Paper Notation for Representing Electrical Charge States

The Physics Teacher 55, 470 (2017); 10.1119/1.5008339

SCALE READINGS

The Physics Teacher 55, 454 (2017); 10.1119/1.5008332

Helping Students Draw Correct Free-Body Diagrams

The Physics Teacher 55, 485 (2017); 10.1119/1.5008345

A New Take on Exploding Carts

The Physics Teacher 55, 475 (2017); 10.1119/1.5008341

\section{Make the Switch: Modular Circuits Untangle your circuits $\underbrace{}_{\substack{\text { tatring } \\ \text { from }}} \mathbf{1 5 9}$}
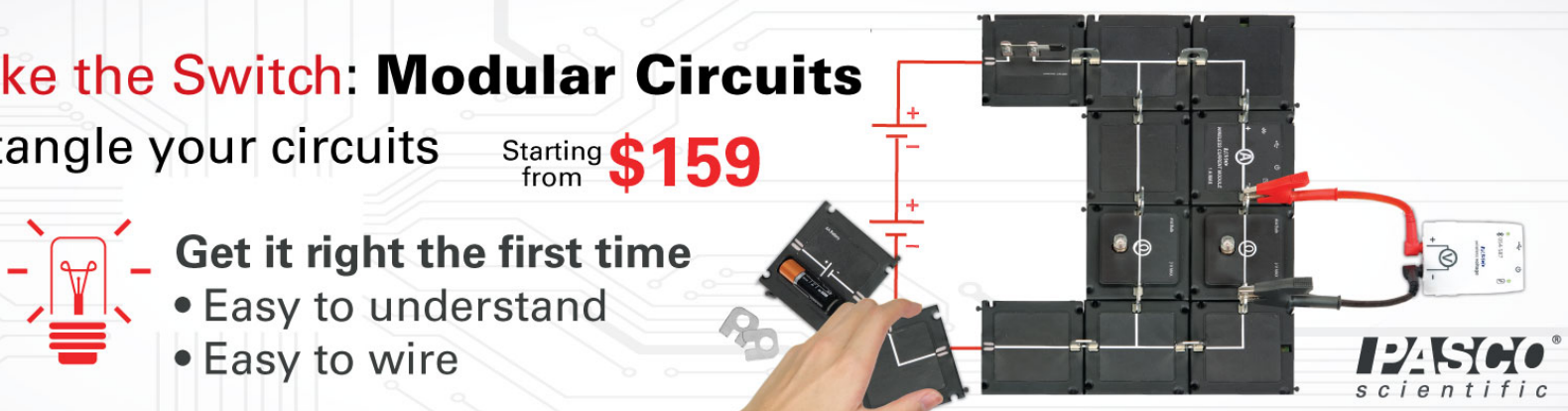


\section{Perspectives on the}

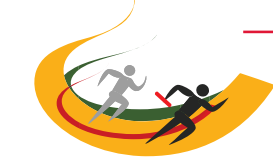

This colorful graphic signals that this contribution is a featured part of the "Race and Physics Teaching" special collection. See the editorial from the Indigenous Worldviews in September 2017 issue of TPT for more details.

\section{Informal Science Education}

\section{Conference}

Aparna Venkatesan, University of San Francisco, San Francisco, CA

Adam Burgasser, UC San Diego, San Diego, CA

$\mathrm{T}$ he chronic underrepresentation of Native and indigenous peoples in STEM fields (Fig. 1) has been a longstanding issue in the United States, ${ }^{2,3}$ despite concentrated efforts by many local and national groups, including the Society for Advancement of Chicanos/Hispanics and Native Americans in Science (SACNAS) and the American Indian Science and Engineering Society (AISES) to address it. Here we report on the conference on Indigenous Worldviews in Informal Science Education (I-WISE), convened in Albuquerque, NM, on Sept. 2-5, 2015. We share what we learned on the commonalities and differences in perspectives between indigenous knowledge (IK) and Western science; summarize the role that IK is already playing in scientific fields, ranging from astrophysics to medicine to climate change; and describe how IK can help science education and research be more sustainable, inclusive, and respectful to all peoples.

\section{The 2015 I-WISE Conference: Background}

Funded by the National Science Foundation (NSF) Advancing Informal STEM Learning (AISL) program, and cosponsored by the 'Imiloa Astronomy Center at the University of Hawai' $i$ at Hilo, $\mathrm{HI}$, and the Indigenous Education Institute (IEI) at Friday Harbor, WA, the 2015 I-WISE conference brought together about 100 scientists, teachers (high school through college/university), students, museum and library staff, and indigenous community leaders from many tribes and nations, some as far away as New Zealand. The uniqueness of this conference lay in addressing not only the underrepresentation of Native/indigenous people in science, but in opening up the discussion more broadly to include the convergence and divergence of Native and Western perspectives in science, and STEM learning and practices. ${ }^{4-5}$ Both authors of this article were present for the meeting, with Venkatesan attending a preconference trip to the Acoma Pueblo (Sky City) on their local Feast Day.

The conference was co-organized by Indigenous-American astronomer Dr. Nancy C. Maryboy (Cherokee/Navajo) from the non-profit organization IEI $^{6}$ (see Additional Resources) and Ka'iu Kimura (Hawaiian), Director of the 'Imiloa Center in Hilo, HI, formally the Maunakea Astronomy Education Center. ${ }^{7}$ The conference was well represented by a range of scientific disciplines, including several professional astronomers and physicists, and educators in these fields.

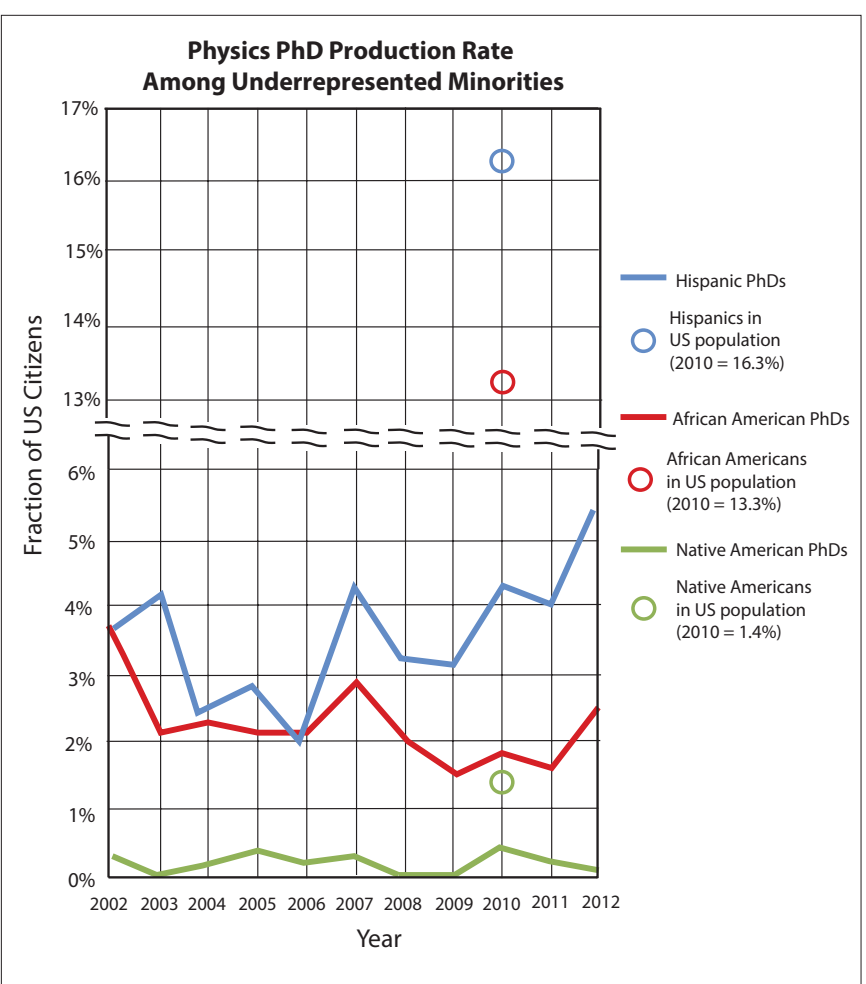

Fig. 1. Percentage of physics PhDs earned by traditionally underrepresented minorities in the United States, based on data from the National Science Foundation National Center for Science and Engineering Statistics report NSF 15-321. ${ }^{1}$

The I-WISE conference was organized around four strands - Holistic Education, Environmental Sustainability, Collaboration with Integrity, and Next Generation Youthand participants engaged in online webinars and discussions for nearly six weeks leading up to the conference. Goals of the conference included understanding the importance of taking into account indigenous worldviews to enhance science literacy and improve STEM education; integrating and synthesizing approaches, methods, and findings of work to date; developing research programs in this area; and developing strategies for lifelong science learning for Native youth.

During the preconference trip to the Acoma Pueblo (Sky City) on the tribe's local Feast Day, conference attendees were warmly welcomed and privileged to view a variety of Pueblo dances and cultural events. We were also given a tour of Aco- 
ma with youth guides who were gifted storytellers, and enjoyed a traditional uber-feast at many of the homes of Acoma Pueblo residents. Many conference participants recalled this as a rich and deeply personal highlight of their conference experience.

\section{Indigenous and Western knowledge per- spectives}

The opening session by Dr. Leroy Littlebear, a member of the Blackfoot tribe, set the stage for the weekend. He opened his talk by thanking the Acoma Pueblo community for allowing us to be present on their territory, which simultaneously recognizes the existence and primacy of indigenous groups in the space. He framed incorporating indigenous worldviews as moving beyond the "Age of Reason"-the dominant 18thcentury Western perspective where rationality and reason alone brings one to truth. As our colleagues in the humanities remind us, objectivity is a myth, since we all approach problems, answers, and situations with the perspectives and biases of the cultures in which we are raised. ${ }^{8,9}$ Our adherence to this worldview-perhaps unconsciously-explains much of the discrimination and exclusion that can occur in science communities and research (e.g., "women are too emotional to be scientists," "he doesn't have the right perspective to do science," or algorithmic discrimination in artificial intelligence technologies $\left.{ }^{10}\right)$. Dr. Littlebear described some of the similarities and distinctions between IK and the Western academic tradition, which we have summarized in Table I. He emphasized that the Native paradigm is necessary to evolve beyond the Age of Reason to a thought system that is more comprehensive, holistic, and relevant for all people in the 21st century.

\section{Conference strands; Space and Place}

Among the four conference strands, we focused on attending two specific strands at the conference: Collaboration with Integrity and Next Generation Youth.

The governing question of the first strand was, "What does it look like to co-create and honor different and complementary value systems, and to develop meaningful relationships?" Discussions were facilitated by conference participants who are longtime advocates for IK within and beyond academia. This session, which had many astrophysicists present, included a deeply honest and heartfelt discussion of the indigenous and academic perspective on the role of the Thirty Meter Telescope (TMT) in Hawai'i, whose construction has stimulated considerable controversy among both astronomers and the Hawaiian community. ${ }^{15}$ The discussion was led by indigenous-American astrophysicist Prof. Paul Coleman (U. Hawaii), Dr. Isabel Hawkins (San Francisco Exploratorium), Dr. Laura Peticolas (SSL, UC Berkeley), Dr. Verlie Ann Malina-Wright (chair of Pacific American Foundation), and Ms.

\section{Table I. Comparing indigenous and Western knowledge.}

\section{Commonalities}

- Oral traditions and storytelling as a way of life and communication. Whether this takes the form of a Native or tribal creation story, or Big Bang cosmology, we share the tradition of passing on the story of our knowledge and our broader context.

- Learning as a measure of being alive (e.g., "when you stop learning, you die").

- Youth leadership. Junior folks are the peers of, or sometimes even lead, the elders.

- Assessment and re-evaluating evaluation. In the IK context this is framed as lived or shared experience; in the Western context this is framed as testing hypotheses with evidence.

- The power of language. Specifically, that some languages describe mathematical and scientific concepts more effectively than English (e.g., Chinese counting system, ${ }^{11}$ deaf sign language for physics concepts ${ }^{12}$ ).

\section{Distinctions}

- Chaos and order. In Western culture, the world is viewed as chaos and complexity overlying a fundamentally ordered system at the smallest scales (e.g., the standard model); in IK, order emerges on large scales from underlying and fundamental chaos and flux.

- The nature of knowledge. IK sees knowledge as holistic and renewing; Western science approaches knowledge from reductionist and cumulative perspectives. In particular, IK integrates wholeness, spirituality, and relationships into its worldview, whereas Western science aims to separate and isolate these aspects.

- Exploration vs. sustainability. Western science is often motivated by "let's do this and see what happens"; a Native scientist will ask "what factors are necessary for our existence?"

- Process vs. product. Western knowledge-making is often a goal- or results-oriented process, leading to a "tyranny of the outcome" (consider how we justify funding). IK knowledge-making is more process and people oriented, growing from developing relationships. This results in much longer timescales for learning and development, and less rigid definitions for progress. The longer timescales for sustainable outcomes in IK practices do not align with the practices of Western institutions and national granting agencies.

- Classification vs. relationship. Much of Western science builds from an edifice of classification - of species, of stars - whereas IK focuses on relationships, allowing for a greater fluidity of definition.

- The myth of lone achievement. A powerful myth of Western achievement is the self- focused, self-driven, solitary genius, ${ }^{13}$ whereas the medium and measure of IK success is contained within a community. Isolation runs as a common (negative) theme in the low numbers of underrepresented minorities in STEM.

- Collaboration vs. assimilation. In Western scientific culture, there are established norms of the community that may suppress novel, creative thought ${ }^{14}$; in IK, science knowing is a dynamic ecosystem that reflects the differing viewpoints within (Littlebear: "Uniformity is the path to the end.").

- Place and space. Learning in harmony with a particular place and time is a key aspect of IK and indigenous identity, reflected in the diversity of architecture of buildings and monuments of indigenous cultures on all continents, in contrast with the building you are likely working in now. 
Kimura. Dr. Malina-Wright is a $k \bar{u} p u n a^{16}$ who has worked with dozens of schools and universities in Hawaii and the mainland. One especially relevant, and sensitive, IK concept to this discussion for astrophysicists is "Space and Place." As Littlebear noted, "Indian Thought is about space referencing" including the home, the land, and sites sacred to each people. This is highly relevant to the future of astronomical facilities such as the TMT and established facilities such as Mount Graham and Kitt Peak, all located on indigenous lands (Hawaiian, San Carlos Apaches, and the Tohono O'odham nation, respectively). As ground-based facilities increasingly shift to more remote and tribal/indigenous lands, it is essential that we honor these sacred spaces and develop a 21st-century model that can work with traditions and shared resources. The challenge is to find mutual understanding and consensus when scientific progress from one perspective is desecration of a sacred place in another, especially for those who have been historically disempowered or marginalized.

\section{Looking ahead: Inclusive sustainable partnerships}

Traditional IK values such as partnership, deep listening, and sustainability have become 21 st-century survival principles. Like the depletion of arable land in the American Midwest or the disappearance of coral reefs worldwide, when indigenous cultures, languages, and ideas disappear, there is profound sickness in the broader ecology ${ }^{17}$ and a true loss of knowledge. We can learn from IK concepts on how to evolve the process and culture of science into a living ecosystem, rather than a process of assimilation and isolation. To do this, those of us in "mainstream" Western science must be willing to learn and to be transformed by IK, as individuals and institutions. As Dr. Robert Russell, representative from the NSF, noted in his talk during the conference, it's not just an issue of equity, representation, and needing more Native scientists or more scientists overall; we truly need the indigenous perspective and its wisdom to continue the science endeavor in a sustainable way.

The 2015 I-WISE conference was the first stage in examining IK and Western science perspectives and developing potential cooperative models between educators and communities for the 21st century. Results from the strand discussions are now available online, ${ }^{18}$ and are excellent resources for assessing and evolving your local institution or environment through IK practices. The 2016 I-WISE conference in Washington, DC, concluded with the goal of formulating a research agenda in informal science learning. ${ }^{19}$ Expect to hear more about the role IK can and should play in making our science enterprise sustainable, inclusive, and respectful to all peoples.

\section{References}

1. National Science Foundation National Center for Science and Engineering Statistics, "Science and Engineering Degrees, by Race/Ethnicity of Recipients: 2002-12 (NSF 15-321)," https:// www.nsf.gov/statistics/2015/nsf15321/\#chp2, accessed June 17, 2017.

2. Vimal Patel, "Why so few American Indians earn Ph.D.s, and what colleges can do about it," Chron. High. Educ. (2014), http://chronicle.com/article/Why-So-Few- American-Indians/146715, accessed Aug. 18, 2016.

3. Calvin Ortega Jr., "Why so few Native American astronomers? One student's perspective," Spectrum Newsletter (AAS, Washington, DC, Jan. 2014).

4. G. A. Cajete, Igniting the Sparkle: An Indigenous Science Education Model (Kivakí Press, Skyand, NC, 1999).

5. M. Bang, D. Medin, K. Washinawatok, and S. Chapman, "Innovations in Culturally Based Science Education Through Partnerships and Community," in New Science of Learning: Cognition, Computers and Collaboration in Education, edited by M. Khine and I. Saleh (Springer, New York, 2010).

6. “About the Indigenous Education Institute," http:// indigenousedu.org/wp/about-iei, accessed Aug. 18, 2016.

7. "Mission and History of the 'Imiloa Center," http://www. imiloahawaii.org/104/mission- history, accessed Aug.18, 2016.

8. Ian I. Mitroff, "The myth of objectivity or why science needs a new psychology of science," Manage. Sci. 18 (10), B613-B618 (1972).

9. Kenneth O. Stanley and Joel Lehman, Why Greatness Cannot Be Planned: The Myth of the Objective (Springer, New York, 2015).

10. Solon Barocas and Andrew Selbst, "Big data's disparate impact," California Law Rev. 104, 671 (2016).

11. Yiyuan Tang et al., "Arithmetic processing in the brain shaped by cultures," Proc. Natl. Acad. Sci. 103 (28), 10775-10780 (2006).

12. Jessica Griggs, "Obscure physics words get sign language equivalents," New Scientist Daily News (June 30, 2012), https:// www.newscientist.com/article/dn21967-obscure- physicswords-get-sign-language-equivalents, accessed Aug. 18, 2016.

13. Sarah-Jane Leslie, Andrei Cimpian, Meredith Meyer, and Edward Freeland, "Expectations of brilliance underlie gender distributions across academic disciplines," Sci. 347 (6219), 262-265 (2015).

14. Fred Southwick, "Opinion: Academia suppresses creativity," The Scientist (May 9, 2012), http://www.the-scientist. com/?articles.view/articleNo/32077/title/Opinion--AcademiaSuppresses-Creativity, accessed Aug. 18, 2016.

15. Alexandra Witze, "The mountain-top battle over the Thirty Meter Telescope," Nat. 526, 24-26 (2015).

16. Küpuna can be formally defined as a grandparent, grandaunt/ uncle, or ancestor, but generally also conveys the idea that such people are the carriers and teachers of prior knowledge. Based on Ulukau-Hawaiian Electronic Library Hawaiian Dictionaries, http://wehewehe.org/gsdl2.85/cgi-bin/ hdict? $\mathrm{a}=\mathrm{d} \& \mathrm{~d}=\mathrm{D} 10044$, accessed Oct. 3, 2017.

17. This sickness has a literal manifestation in climate change, whose rapid consequences have disproportionately affected indigenous peoples. See Jay Williams, “The impact of climate change on indigenous people-The implications for the cultural, spiritual, economic and legal rights of indigenous people," Int. J. Hum. Rights 16, 648 (2012).

18. "Strand Session Reports from Albuquerque," http:// iwiseconference.org/strand- session-reports-from-albuquerque/, accessed Aug. 18, 2016.

19. Ibid. 


\section{Additional resources:}

- I-WISE Conference website: http://iwiseconference.org/

- Links to the presentations by the speakers and other resources: http://iwiseconference.org/resources/

- Indigenous Education Institute (IEI): http://indigenousedu. org/

- Dr. Nancy Maryboy and Dr. David Begay are the co-founders of the IEI, an organization based in Washington state whose mission is "to preserve, protect and apply traditional Indigenous knowledge in a contemporary setting," ${ }^{3}$ and which has led several efforts to apply traditional knowledge to areas such as astronomy and other science disciplines. IEI has developed a planetarium show, Navajo Sky, funded by NASA, and has published Sharing the Skies: Navajo Astronomy. (http://www. sharingtheskies.com).

- For more information/resources on including the indigenous perspective in the classroom or in schools/institutions, please see these links from the IEI, or directly contact Dr. Maryboy (wohali7@gmail.com) or Dr. Begay (dbegay@gmail.com).

- Cosmic Serpent (NSF No. DRL-0714631 and DRL-0714629, http://www.cosmicserpent.org) is a professional development effort led by the IEI and the University of California at Berkeley that supports collaboration between science museum professionals and Native communities and/or tribal museums.

- One example of IEI partnering with an existing education/ outreach program: The Imagine Mars through Native Eyes Project, supported by the NASA MAVEN mission: http:// indigenousedu.org/wp/imagine-mars-through-native-eyes/.

- 'Imiloa Center in Hilo, HI: http://www.imiloahawaii.org. Its mission is "to honor Maunakea by sharing Hawaiian culture and science to inspire exploration," 6 and is organized around the principles of 'imiloa (exploration driven by wonder), na'auao (authentic, inspiring education), hookipa (hospitality and respect), alulike (teamwork toward improvement), and no'onoo 'palau (bilingual fluency).

- Dr. Adam Burgasser's UCSD Senior Seminar on Indigenous Science, aimed at exploring indigenous and Western approaches to the scientific understanding of the world around us (includes a resource list): http://pono.ucsd.edu/ adam/wordpress/indigenousknowing/

- A resource on reasons to integrate IK with science curricula, from Canada-based Indigenous Corporate Training: https:// www.ictinc.ca/blog/7-reasons-to-integrate-indigenousknowledge-into-science- curriculum

- NSF Advancing Informal STEM Learning: https://www.nsf. gov/funding/pgm_summ.jsp?pims_id=504793

- Society for Advancement of Chicanos and Native Americans in Science (SACNAS): https://sacnas.org/

- American Indian Science and Engineering Society (AISES): http://www.aises.org/

- Sloan Indigenous Graduate Partnership (SIGP): http:// sloanphds.org/sloan-indigenous-graduate-program.html

- Harlow Shapley Visiting Lectureship administered through the American Astronomical Society (AAS): https://aas.org/ outreach/harlow-shapley-visiting-lectureships-astronomy. Consider visiting and teaching at a tribal college through this lectureship, which supports a program of two-day visits by professional astrophysicists to two-year colleges and four-year undergraduate institutions throughout North America, including Canada and Mexico, and especially institutions that do not offer an astronomy degree.

Aparna Venkatesan is an associate professor of physics and astronomy at the University of San Francisco. She conducts research in cosmology, has worked with Native American youth, and teaches about indigenous/ Native American perspectives in science. avenkatesan@usfca.edu

Adam Burgasser is a professor of physics at UC San Diego who conducts research in astrophysics and physics education. He is a member and former chair of the American Astronomical Society Committee on the Status of Minorities in Astronomy and co-director of the UCSD-MorehouseSpelman Physics Bridge Program. aburgasser@ucsd.edu 